\title{
Effects of Europium-Barium Nonstoichiometry in EBCO123 Systems on Transition and Magnetization Properties
}

A. Cigáň, J. Maňka, M. Kopčok, J. Polovková, P. Jurdák AND A. KOŇAKOVSKÝ

Institute of Measurement Science, Slovak Academy of Sciences Dúbravská cesta 9,84104 Bratislava, Slovakia

We studied the effects of $\mathrm{Eu}-\mathrm{Ba}$ nonstoichiometry in two series of $\mathrm{Eu}_{1+x} \mathrm{Ba}_{2-x} \mathrm{Cu}_{3} \mathrm{O}_{7-\delta}$ and $\mathrm{Eu}_{1-x} \mathrm{Ba}_{2+x} \mathrm{Cu}_{3} \mathrm{O}_{7-\delta}$ samples on transition, structural, and magnetic properties. The samples with the nominal composition of $0 \leq x \leq 0.07$ were synthesized by the solid-state reaction method from $\mathrm{Eu}_{2} \mathrm{O}_{3}, \mathrm{BaCO}_{3}$, and $\mathrm{CuO}$ precursors and sintered at $1050^{\circ} \mathrm{C}$ for $72 \mathrm{~h}$ in flowing oxygen. All the samples show the values of critical temperature $T_{\mathrm{c}}$, volume density $\rho$, and maximum volume magnetization $M_{\max }$ higher than $90 \mathrm{~K}, 6.3 \mathrm{~g} \mathrm{~cm}^{-3}$ and $10^{4} \mathrm{Am}^{-1}$, respectively, except for $x=0.07$ samples. The $\mathrm{Eu}-\mathrm{Ba}$ nonstoichiometry in the two series shows different effects on transport, magnetization hystereses, and intergrain properties of the samples.

PACS numbers: 74.72.-h, 74.62.Bf, 74.25.Fy, 74.25.Ha

\section{Introduction}

High- $T_{\mathrm{c}} \mathrm{LREBa}_{2} \mathrm{Cu}_{3} \mathrm{O}_{7-\delta}$ superconductors, where LRE is a light rare element such as $\mathrm{Nd}, \mathrm{Eu}, \mathrm{Sm}$, are known to exhibit higher $T_{\mathrm{c}}$, critical current density $j_{\mathrm{c}}$, and irreversibility field than $\mathrm{YBa}_{2} \mathrm{Cu}_{3} \mathrm{O}_{7-\delta}$. However, while the last system is stoichiometric, in the former systems, $\mathrm{LRE}_{1+x} \mathrm{Ba}_{2-x} \mathrm{Cu}_{3} \mathrm{O}_{7-\delta}$ solid solutions can be formed. In this systems, LRE-Ba substitution can take place due to a small difference in the ionic radius between $\mathrm{LRE}^{3+}$ and $\mathrm{Ba}^{2+}$ ions. The increasing occupation of $\mathrm{Ba}^{2+}$ sites by $\mathrm{LRE}^{3+}$ ions results in a sharp deterioration of some superconducting properties, e.g., $T_{\mathrm{c}}, j_{\mathrm{c}}$ at higher LRE-Ba substitution levels. Nevertheless, the LRE-Ba substitution leads also to local composition fluctuations, which can play a positive role in formation of the so-called $\partial T$-pinning centres of magnetic field, increasing $j_{\mathrm{c}}[1]$. On the other hand, an addition of Ba-containing precursors is one of the ways of preventing the LRE-Ba substitution [2]. For the 
above reasons, it is interesting to study nonstoichiometric $\mathrm{LRE}_{1+x} \mathrm{Ba}_{2-x} \mathrm{Cu}_{3} \mathrm{O}_{7-\delta}$ systems.

In addition, a systematic study of the systems has not been performed yet and their properties are strongly dependent on parameters of technological procedures.

In this paper, we present results of a systematic study of $\mathrm{Eu}-\mathrm{Ba}$ nonstoichiometry in two series of samples, one series $\mathrm{Eu}_{1+x} \mathrm{Ba}_{2-x} \mathrm{Cu}_{3} \mathrm{O}_{7-\delta}$, and another one $\mathrm{Eu}_{1-x} \mathrm{Ba}_{2+x} \mathrm{Cu}_{3} \mathrm{O}_{7-\delta}$, where $0 \leq x \leq 0.07$.

\section{Experimental}

Samples with nominal composition $\mathrm{Eu}_{1+x} \mathrm{Ba}_{2-x} \mathrm{Cu}_{3} \mathrm{O}_{7-\delta}$ and $\mathrm{Eu}_{1-x} \mathrm{Ba}_{2+x}-$ $\mathrm{Cu}_{3} \mathrm{O}_{7-\delta}$, where $0 \leq x \leq 0.07$, have been prepared by a standard solid-state reaction method from $\mathrm{Eu}_{2} \mathrm{O}_{3}, \mathrm{BaCO}_{3}$, and $\mathrm{CuO}$ precursors. The mixture in appropriate weight amounts has been homogenized in an agate mortar and calcined in air at $930^{\circ} \mathrm{C}$ for $40 \mathrm{~h}$. The obtained precursors have again been homogenized in the agate mortar, pressed into pellets (with the diameter of $12 \mathrm{~mm}$ ) under the pressure of $200 \mathrm{MPa}$ and sintered in flowing oxygen $(10 \mathrm{ml} / \mathrm{min})$ at $1050^{\circ} \mathrm{C}$ for $72 \mathrm{~h}$; then cooled to $580^{\circ} \mathrm{C}$ and held at this temperature for $24 \mathrm{~h}$, and thereafter cooled in a furnace to the room temperature. The mass of sintered samples was about $1.28 \mathrm{~g}$. The critical temperature $T_{\mathrm{c}}(\mathrm{R}=0)$ of the samples was determined by a standard resistance four-point method and the transition width $\Delta T_{\mathrm{c}}$, was characterized by the $10-90 \%$ criterion. The phase composition was studied by X-ray diffraction measurements $\left(\mathrm{Cu} K_{\alpha}\right.$ radiation $)$ from powdered samples. AC volume magnetization characteristics were measured in detail by a compensation method using a second-order SQUID gradiometer [3]. All magnetization characteristics were measured at $77.3 \mathrm{~K}$ after the zero-field cooling in applied magnetization field $H_{\mathrm{a}}$ with the frequency of $0.1 \mathrm{~Hz}$ and amplitude ranging from $10^{-1}$ to $10^{5} \mathrm{Am}^{-1}$. $H_{\mathrm{a}}$ was parallel to the axis of the sample. The demagnetizing factor was determined from the geometry of the sample. The first penetration magnetic field $H_{\mathrm{pl}}$ of the intergrain weak link network and the magnetic susceptibility $\chi$ were determined from the first deviation from the linear behaviour of the virgin magnetization curves.

\section{Results and discussion}

The resistance $R$ vs. temperature $T$ dependences of the $\mathrm{Eu}_{1+x} \mathrm{Ba}_{2-x^{-}}$ $\mathrm{Cu}_{3} \mathrm{O}_{7-\delta}$, and $\mathrm{Eu}_{1-x} \mathrm{Ba}_{2+x} \mathrm{Cu}_{3} \mathrm{O}_{7-\delta}$ samples with $x=0.0,0.01,0.040 .05$, and 0.07 are shown in Fig. 1a and b, respectively. All the samples show the linear temperature dependence of $R$ in a broad temperature range, except for the Ba-rich sample $(x=0.07)$. The values of $T_{\mathrm{c}}$ and $\Delta T_{\mathrm{c}}$ are in the intervals of $91.4-93.4 \mathrm{~K}$ and 1.6-1.2 K, respectively for the $\mathrm{Eu}_{1+x} \mathrm{Ba}_{2-x} \mathrm{Cu}_{3} \mathrm{O}_{7-\delta}$ samples and 90.2-92.4 $\mathrm{K}$ and 1.6-1.2 K, respectively for $\mathrm{Eu}_{1-x} \mathrm{Ba}_{2+x} \mathrm{Cu}_{3} \mathrm{O}_{7-\delta}$ samples, except for the sample with $x=0.07$ with $T_{\mathrm{c}}$ and $\Delta T_{\mathrm{c}}$ of $87.5 \mathrm{~K}$ and $1.9 \mathrm{~K}$, respectively. 
For the systems with excess $\mathrm{Eu}$ and $\mathrm{Ba}$, there are evident opposed trends of a decrease resp. increase in the zero temperature resistance $R_{0}$ extrapolated from the linear part of $R(T)$ dependence and normal resistances (Fig. 1) with a growth of $x$. From powder X-ray diffraction data, it can be concluded that single phased samples were obtained for all $\mathrm{x}$ values in $\mathrm{Eu}_{1-x} \mathrm{Ba}_{2+x} \mathrm{Cu}_{3} \mathrm{O}_{7-\delta}$ compounds. This applies also to $\mathrm{Eu}_{1+x} \mathrm{Ba}_{2-x} \mathrm{Cu}_{3} \mathrm{O}_{7-\delta}$ samples. However, an impurity phase was detected from $x=0.05$, which was quite unexpected since the forming of a solid solution in air in the system was reported up to $x \sim 0.4$ [4]. In the near future, we want to verify or identify the presence of the impurity phase in repeated syntheses.
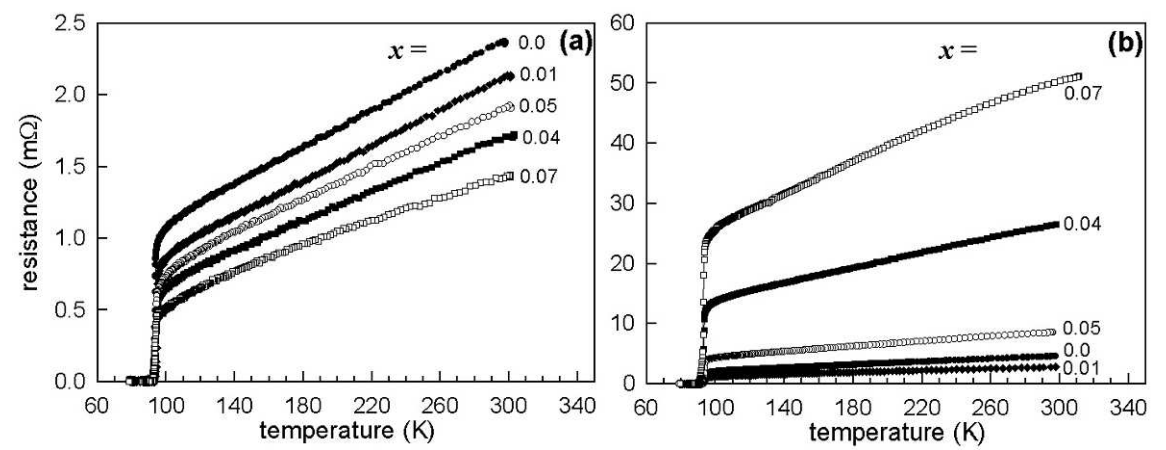

Fig. 1. $R$ vs. $T$ dependences of $\mathrm{Eu}_{1+x} \mathrm{Ba}_{2-x} \mathrm{Cu}_{3} \mathrm{O}_{7-\delta}$ (a) and $\mathrm{Eu}_{1-x} \mathrm{Ba}_{2+x} \mathrm{Cu}_{3} \mathrm{O}_{7-\delta}$ (b), samples with $x=0,0.01,0.04,0.05$, and 0.07 .

The hystereses curves $M$ vs. $H_{\mathrm{a}}$ of samples with the nominal composition of $\mathrm{Eu}_{1+x} \mathrm{Ba}_{2-x} \mathrm{Cu}_{3} \mathrm{O}_{7-\delta}$ and $\mathrm{Eu}_{1-x} \mathrm{Ba}_{2+x} \mathrm{Cu}_{3} \mathrm{O}_{7-\delta}$ for $x=0,0.05$, and 0.07 are shown in Fig. 2a and b, respectively, for given amplitude of $H_{\mathrm{a}}$. All the samples show the $Z$-shape magnetization curves typical of polycrystalline samples. $M-H$ curves are approximately the same and $M_{\max }$ is higher than $10^{4} \mathrm{Am}^{-1}$, except for the Eu-rich sample with $x=0.07$, which shows an already significantly lower value. On the other hand, magnetization hystereses of the $\mathrm{Eu}_{1+x} \mathrm{Ba}_{2-x} \mathrm{Cu}_{3} \mathrm{O}_{7-\delta}$ samples increase with $x$ up to $x \leq 0.5$; see also Fig. 2a. The increasing magnetization hysteresis supports a growth of values of the grain- and intergrain $j_{\mathrm{c}}$. The former could be related to the creation of new pinning centres by the composition fluctuations for lower $x$ and/or forming of the impurity phase for $x \geq 0.05$. Adding an excess Eu has also a positive effect on intergrain properties. There is a trend of increasing the penetration field $H_{\mathrm{pl}}$ from $450 \mathrm{Am}^{-1}$ to $1110 \mathrm{Am}^{-1}$ with $x$ from zero to $x=0.05$. Samples with excess of Ba show an opposite trend of a decrease in $H_{\mathrm{pl}}$ from $580 \mathrm{Am}^{-1}$ to $120 \mathrm{Am}^{-1}$. Results of optical polarization microscopy show no significant effect of Eu doping on the microstructure of $\mathrm{Eu}_{1+x} \mathrm{Ba}_{2-x} \mathrm{Cu}_{3} \mathrm{O}_{7-\delta}$ samples. On the contrary, an increasing Ba-content leads to a structure disintegration and an increase in small-sized grains. 
Generally, it seems that excess Eu leads to a structural ordering, e.g., the filling-up vacancies in the $\mathrm{Cu}-\mathrm{O}$ chains using excess oxygen [5], better homogeneity, and tight distribution of intergrain links contrary to Ba-excess samples.
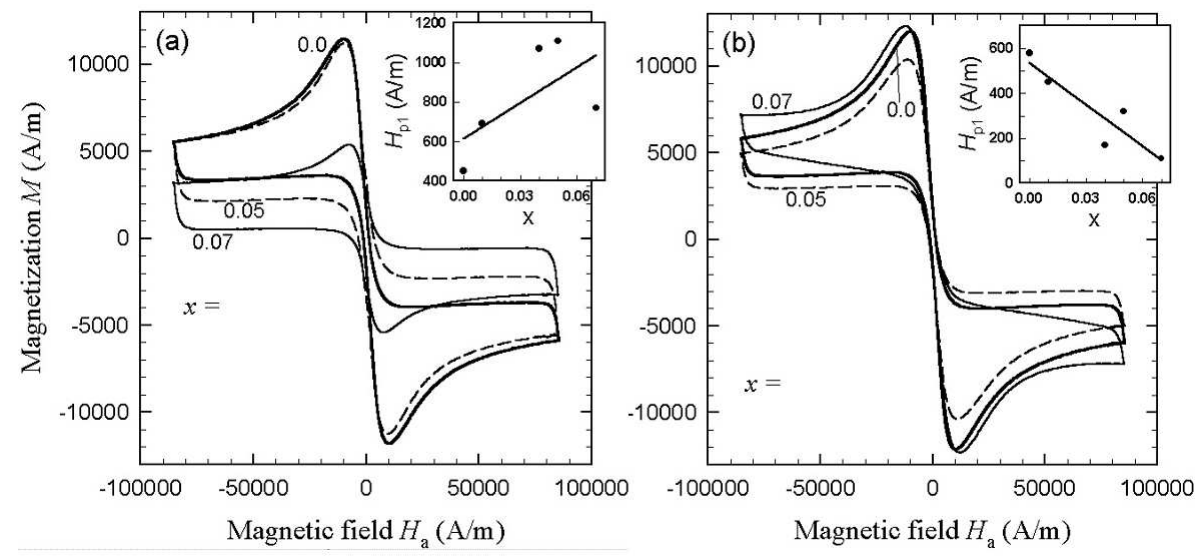

Fig. 2. $M$ vs. $H_{\text {a }}$ dependences of $\mathrm{Eu}_{1+x} \mathrm{Ba}_{2-x} \mathrm{Cu}_{3} \mathrm{O}_{7-\delta}$ (a) and $\mathrm{Eu}_{1-x} \mathrm{Ba}_{2+x} \mathrm{Cu}_{3} \mathrm{O}_{7-\delta}$ (b) for the samples with $x=0,0.05$, and 0.07 .

\section{Conclusions}

We studied the effects of nonstoichiometry in $\mathrm{Eu}_{1+x} \mathrm{Ba}_{2-x} \mathrm{Cu}_{3} \mathrm{O}_{7-\delta}$ and $\mathrm{Eu}_{1-x} \mathrm{Ba}_{2+x} \mathrm{Cu}_{3} \mathrm{O}_{7-\delta}$ systems, $0 \leq x \leq 0.07$. Increasing $x$ leads to different behaviours in the two systems. In the former system, evident trends of a decrease in the extrapolated resistance $R_{0}$, improvement of normal resistances, and intergrain properties, (e.g., $\left.H_{\mathrm{p} 1}\right)$ are observed with $x$ up to $x=0.05$, and vice versa in the last system, while $T_{\mathrm{c}}$ is still above $90 \mathrm{~K}$.

\section{Acknowledgements}

This work was supported by the Slovak Grant Agency for Science, project $2 / 7083 / 27$.

\section{References}

[1] A. Hu, M.R. Koblischka, X. Yao, H. Zhou, M, Winter, U. Hartmann, M. Murakami, Supercond. Sci. Technol 19, S580 (2006).

[2] D.A. Cardwell, N.H. Babu, Y. Shi, K. Iida, Supercond. Sci. Technol 19, S510 (2006).

[3] V. Zrubec, A. Cigáň, and J. Maňka, Physica C 223, 90 (1994).

[4] M. Murakami, N. Sakai, T. Higuchi, S.I. Yoo, Supercond. Sci. Technol 9, S510 (1996).

[5] A. Gupta, V.P.S. Awana, S.B. Samanta,H. Kisham, A.V.Narlikar, in: Frontiers in Superconducting Materials, Ed. A.V. Narlikar, Springer, Berlin 2005, p. 499. 